\title{
SUSTAINABILITY AND REGIONAL DEVELOPMENT: THE CASE OF THE TOURISM SECTOR IN SOUTHERN EUROPE
}

\section{MODINOS}

Received: 30/06/99

President of IN.I.E.R.

Accepted: 20/02/01

Tositsa 28

GR - 10683 Athens, Greece

\section{ABSTRACT}

The present work argues that sustainable tourism is essential to the long-term survival of the tourism industry in Europe. Sustainable tourism may be regarded as a means of redressing economic imbalances between European regions and nations without producing adverse environmental, social and cultural effects on host communities. Conflicts between the development of a local economy and the interests of 'outside' investors from elsewhere among EU member nations must be resolved in the best interests of the local people and the environment. The degree to which profits are expropriated from a local area or region is a particular concern. The transnational character of tourism businesses makes necessary a European-wide policy, where the quality of life and nature's conservation will obtain a premortial place.

KEYWORDS: Environmental planning, natural resources and ecosystems management, sustainable development, tourism industry, environmental economics.

\section{INTRODUCTION}

Success in the tourism sector lies in maintaining vibrant and healthy natural, cultural and social environments. Primarily the offer depends upon the quality of conditions in any given tourism destination. It is this quality more than any other factor, which determines the market value. In the case of the Southern Europe, it is their rich natural and historical patrimony that has long been an attraction to visitors. During the last fifty years, the Mediterranean regions had gained the position of being the traditional stronghold of summer season tourism and have been, and continue to be, developed to cater to increasing numbers of visitors. In the development process, the focus has most frequently been on short and medium term investment bringing a rapid return in profits. Development of superstructure has been extensive, often with disregard or lack of foresight as to the overall effect on local conditions. The nature of development in many tourism destinations has been such that the corresponding deterioration of the environment is of a scale that has not only caused conflict amongst local communities but has also placed in jeopardy the attractions which draw the visitor. Furthermore, competition from new and emerging destinations in the rapidly expanding long-haul market now threatens the economic stability of some communities and regions dependent on tourism as a leading economic generator and income provider.

Sustainable tourism has become, in view of the 
above, a catchword and a platform for discussing a reorientation of regional development policies. In fact, it attempts to face the risk of abandonment of a destination, which increases by the deteriorating environmental conditions. Once a destination is labelled as deteriorated, the recovery to a leading market position is difficult to achieve. The tour operator however suffers only a temporary inconvenience as the promotion of offers and the use of carriers can simply be switched to other destinations. Unless having considerable real estate investment in any destination, the tour operator's main consideration is that the carrier is full to passenger capacity. Recent research has revealed that neither the tour operator, travel agencies nor transportation companies accept responsibility for the conditions of the environment at destinations where they operate (Hemingway, 1997).

If we codify the problems arising from overdevelopment in Southern European destinations that are purpose built for tourism we will read them as follows (Hemingway, 1997):

- Degradation of natural surroundings and manmade historic and cultural patrimony

- Destruction of wildlife habitats and fragile ecosystems

- Over exploitation of scarce water resources

- Inadequate waste water treatment

- Proliferation of municipal solid wastes and accompanying inadequate disposal facilities

- Dependence of local communities on seasonal tourism as the leading income provider. Underdevelopment of other economic activities.

- Diminishment of traditional forms of earning income such as agriculture, fishing and local production of artisan crafts

- Loss of cultural identity and traditional values of local populations

The listed problems are existent worldwide and not in any way solely to be encountered in Southern European destinations. However, the Mediterranean region, and particularly those traditional destinations developed for the package tour market, mainly entered into business without adequate supportive environmental infrastructure. Many are now in a condition where it is proving an expensive operation to re-fit and upgrade to modern requirements and it is this last which must be met for these destinations to main- tain their economies and acquired standard of living. An appropriate mix of workable legislation and voluntary measures from tourism industry sectors is necessary for Mediterranean destinations to maintain their leading position. Without such information being introduced to decisionmakers, the objective of maintaining economies financed by tourism revenues cannot be achieved. In view of the above let us now review the creation and adoption of the term sustainable development.

\section{THE NEED FOR SUSTAINABILITY IN ITS HISTORIC CONTEXT}

In the present work, sustainable tourism is set within the broader concept of sustainable development, a concept that is evident in policy thinking at a variety of levels, not least in European Union (EU) debates. For instance, the Green Paper from DGXXIII of the European Commission (1995) argues that it is vital for the future of the European tourist industry for it to operate according to the broad principles of sustainable development. Consideration then is given to why it is important to use the concepts of sustainable development and sustainable tourism development. This includes an appraisal of the potential environmental, social, cultural and political benefits and costs of tourism development, as well as of the reasons why the market economy may fail to allocate resources sustainably and why governmental and other interventions are necessary.

Environmental economics provides many valuable arguments in support of the concept of sustainable development and this perspective and the emphasis on environmental resources gives coherence to the analysis of a complex set of issues. Subsequently, the analysis evaluates the wider relevance of sustainable tourism to embrace not just environmental but also social, economic, cultural and political resources (Bramwell et. al., 1995).

The concept of sustainable development was introduced by the World Commission on Environment and Development (1987), which argued that current economic development should be realised taking the coming generations into account. This implies that the external environmental costs of production and consumption should no longer be shifted onto coming genera- 
tions. A question in this respect is whether or not there was a need previously for the formulation of the concept of sustainable development. Were there no appropriate mechanisms and instruments available in traditional economic analyses and theories? Indeed, it is claimed by neo-classical economists that the functioning of market processes will result in an optimal allocation of production factors. However, during the 1980s, it became increasingly clear that traditional market evaluation, including the concept of social costs, did not provide sufficient theoretical underpinning or instruments to stop environmental degradation. The concept of sustainable development has been posed as a solution to the inability of traditional economic theories to deal with these types of problems.

At the United Nations Conference on the Environment and Development held in Rio de Janeiro in 1992, the strategy of sustainable development was described as the essential political model for the $21^{\text {st }}$ century. With this concept extending to all sectors of human life and economic activity, it seemed that an objective of this kind, being designed to secure environmentally compatible development, should also be applied to tourism, as a branch of economic activity.

The expression "sustainable development" is subject to many different interpretations. Below we present the main general maxims for the ensuing action. Structurally these maxims are of wide validity, i.e., they demand a weighing up of any possible nuisances involved in any transaction. Yet, this requires that any conceivable nuisance shall be quantifiable, and moreover that demarcation in terms of time and space is feasible. Ranges of instruments are accordingly required for rendering the theoretical concept operational. After all, the question of applying the concept in the various fields of action in tourism presents itself both to the supplier of tourist services, on the one hand, and to consumers, on the other.

The concept of "Sustainable Tourism" is strongly reminiscent of terms used in the strategic debate of the 1980s on the kind of tourism development to be pursued. Expressions such as "qualitative tourism" or "the gentle tourism" would degenerate into a commonplace of tourism policy and can be regarded as metaphors for new direction in tourism so frequently demanded. This strategic discussion may have produced new solutions in a large number of separate projects, yet new concrete directions for tourism are still lacking. This inevitably raises the question of whether any new general scheme for the global development of human life and economic structures can also engender a new direction for tourism. Therefore, a brief explanation of the concept itself will be required (Lorch et. al., 1995).

In Agenda 21 the initial call for sustainable development ran as follows: the basic developmental parameters for man and the environment must be laid out in such a way to preserve a lasting ability to survive in the human community. This call implies that the continuance of man's current modes of living and production would mean that his existence is no longer assured in the long term. The concept of sustainable development assumes that the survival of mankind would only be possible provided that economic, social and community structures along with all the resulting activities are directed towards the preservation of the biosphere. Current satisfaction of human needs must be directed towards the output of the natural household, so as to ensure that generations to come shall be able to satisfy their needs "in the same way". The concept does not therefore place environmental protection at the centre of all considerations, but promotes usage of a kind directed at preserving those natural potentials of vital importance for mankind. This concept of usage is to be originally found in the forestry industry in the form of a principle familiar there for centuries: if output of timber is to be kept to a maximum in the long term, then the quantities harvested should not exceed the system's regeneration capacity.

Amongst the environmental movement and in scientific circles it is often believed that human husbandry in the form of a circular development must generally be meshed into natural cycles. The bounds of all activities are accordingly determined not by such neo-classical factors as the optimal satisfaction of man's consumer needs or a maximum exploitation of production opportunities, but rather from the finiteness of resources. The concept therefore makes a demand on the count that "All forms of husbandry which can only ensure economic development by the continued depletion of resources and the related increasing strain on the natural environment need to be transformed as soon as possible". This objective can only be achieved by a reduction of 
material inputs and outputs in production processes and services and -consequently- a reduction of the negative repercussions on nature. Economic development shall then be restrained, wherever this jeopardises intact forms of community. The only activities tolerable in the sense of this concept are those compatible with natural circumstances and the communal structure, as formed by human activities and affected by the consequences of these.

Although sustainable development has often been described as a contradiction in terms it offers a valuable common ground for the discussion of the management of natural resources.

\section{A SPATIAL APPROACH OF SUSTAINABLE TOURISM}

Spatial and temporal factors differ in their dependence on the activity concerned and/or the resultant problems. The differences arise from the quantity and quality of the raw materials used (inputs), from the utilisation of residues (outputs), along with the impacts arising from inputs and outputs on environmental conditions and community structures at the place concerned. The greater the input/output quantities and the larger the anticipated negative impacts on nature and society, the more rigorous the scrutiny must be of whether an activity conforms to the concept. This necessarily produces differentiated and regionspecific criteria for the demands to be placed on sustainable development. Where the concept is applied, a decoupling of economic progress from the depletion of resources and environmental harm is no longer justifiable. Sustainability can only be attained provided that the natural, economic and social system is itself stable. This state of affairs exists for so long as the system is in a position to offset changes in a self-regulating manner. In that case, one may speak of environmental social and economic compatibility, or of those conditions, which constitute sustainability. If the spatial dimension is restricted to determining the destination area for a holiday, its structure will be characterised by specific ecological, sociocultural and socio-economic circumstances. The destination will offer the visitor a specific range of services. This may embrace natural elements comprising resources which do not per se bear any direct relationship to tourism, yet become tourist objects through their power to lure tourists, e.g., beautiful scenery, natural landscapes, etc.). Such a range, on the other hand, can be artificially generated by creating such special infrastructure as hotels, communication systems, sports facilities or parks, all of which may incorporate natural resources. An artificial range of this kind may on the one hand be used to satisfy existing demand, and on the other to induce new demand where a destination area is being opened up for the first time. Tourism is after all embedded in a complex of specific economic and social parameters. These affect both its integration into the whole range of sectoral policies on the spot, and the way in which tourism is handled at different political levels. Any realistic understanding of sustainable tourism must adequately reflect these circumstances. Then sustainable tourism could be defined as follows: A development which takes into account not only aspects in visitor origin countries, but the form of outward journey, on the one hand, along with the interests of visitors and residents in a region to be defined. Activities at the destination need to be based on nature's capacity to absorb, whereby consumption of all resources should be as sparing as possible. The objective of such a tourism policy is the lasting fulfilment of the ecological, productive and socio-cultural functions and the redressing of balances (Bramwell, 1996).

As the effects of interventions in, and influences on, nature are not sufficiently known (or are consistently disregarded) an optimum use of natural resources for human production and consumption, as is the claim of neo-classical analyses of regional development and policy recommendations, becomes a problem. Neo-classical optimisation requires insight into the effects of alternative actions on nature (or into the availability of natural resources) with a probability bordering on certainty, or at least with a chance that can be coped with by the theory of probabilities. The former requirement (of probability bordering on certainty) is quite familiar as the well-known assumption of completely informed agents, which means that the problem of flawed ecological knowledge is simply neglected. The latter requirement (based on probability theory) seems more advanced, but still needs far better ecological knowledge than we generally have, in order to construct a distribution of chances of possible ecological states, as a result of human intervention (Drepper and Manson, 1990). 
In general, processes in nature, and hence human interventions in these processes, appear to be hardly predictable for at least three reasons. First, synergetic effects increase the impact on the environment of separate actions. Second, thresholds are very common in ecosystems. Third, many actions have a delayed effect on the environment. It takes decades, for example, before nitrogen from manure and chemical fertilisers is washed from the top into deeper layers of the soil, causing severe nitrate pollution of the groundwater, which serves in most countries as a source of drinking water. Even if nitrogen leakages to the groundwater can be prevented from now on, nitrate pollution of groundwater will increase considerably for decades in the next century. Thresholds, synergetic effects and delayed reactions make for instance the relations between emissions and their effects rather obscure to us. As a result of human actions, ecosystems change much more capriciously than economists normally assume. The neo-classical approach of optimising the use of the natural resources available is senseless so long as we cannot quite accurately assess the amount of natural resources we have. To put it another way, we cannot optimise our "ecological utilisation space" without knowing exactly where its limits are located; exceeding these limits, often implies irreversible effects on nature and a decrease of the available space (Drepper and Mansson, 1990). It becomes clear then that neo-classical approaches fall short in analysing environmental issues and, subsequently, provide a flawed basis for environmental policy. Then the question arises whether an alternative theoretical approach could be developed providing a more appropriate basis for environmental problems. And if this is the case, does this imply that the link between economic theory and environmental policy could be restored?

Numerous starting-points for the development of such an economic theory are suggested in the literature. Boulding (1966) uses the concept of "spaceship earth". Sachs (1984) advocates an ecodevelopment, Yennicke (1983) suggests ecological imperatives for governmental policies,

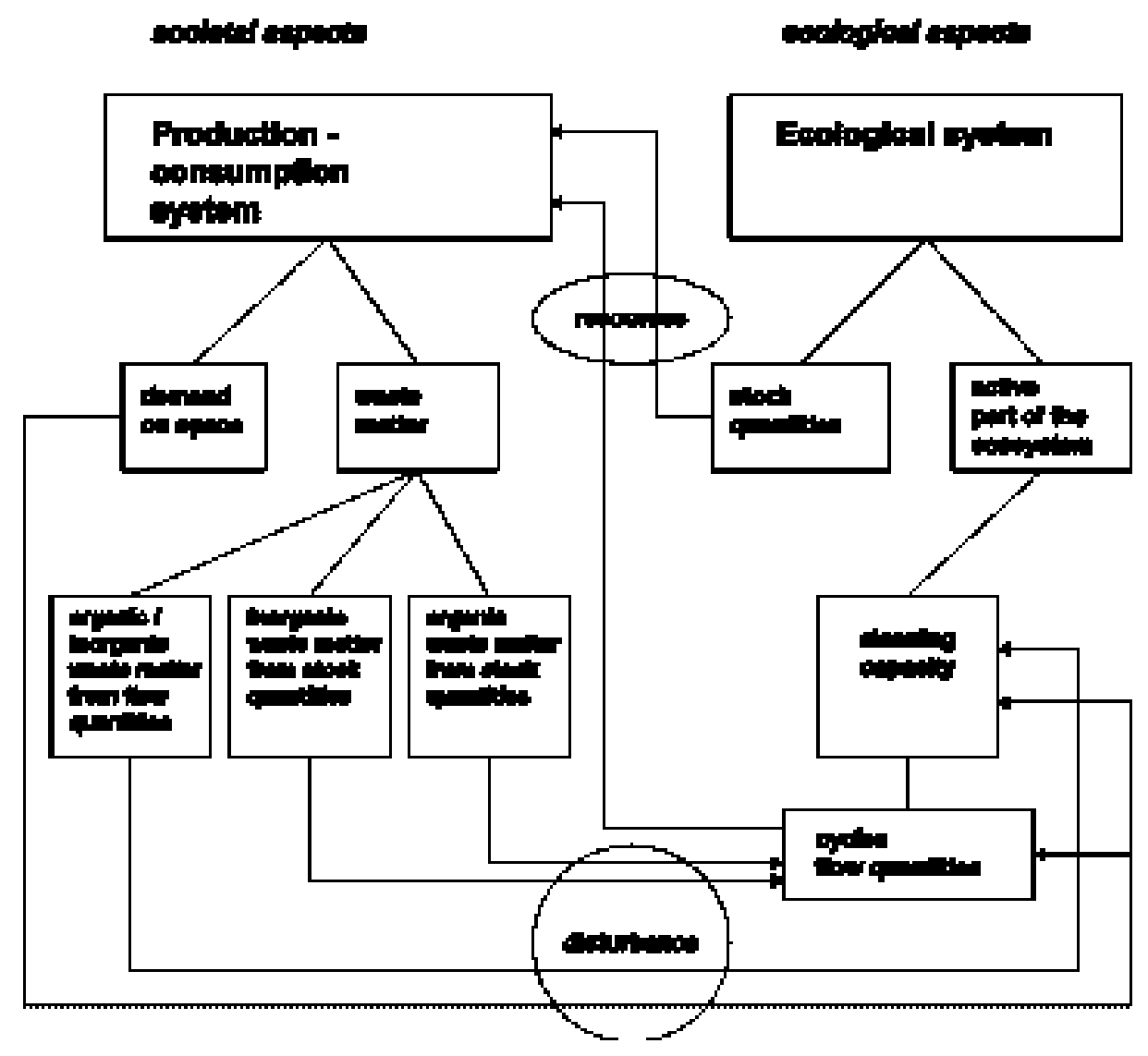

Figure 1. Interactions between the economic and the ecological system (Bramwell et.al., 1996) 
Opschoor (1987-1990) wants to keep economic activities within the limits of the ecological utilisation space, and Brundtland (1987) promotes the concept of sustainable development. The above terms have in common that the ecologically bounded possibilities to the use of natural resources, are taken as a normative starting-point for the development of economic theory. Figure 1 helps to delineate different kinds of effects of human activities on the natural systems.

Special attention has to be paid to one category of effects on nature by human actions: the use of land as this seriously violates the ecosystems and thus threatens the cycles. The process began as soon as people, once settled at fixed residences, took up agriculture and began to change the natural layer of vegetation. In Europe, the process has advanced to the point that hardly any of the original vegetation is left. Modifications in the vegetation need not necessarily lead to unacceptable changes in the natural cycles, but they do interfere with the cyclical process. Further attacks on the natural vegetation by the building of tourist accommodation, the construction of airports and other infrastructures have seriously affected the ecosystem. However, their effect is different from that of the discharges of waste products, in that they threaten the functioning of cycles much faster and more directly, without complicated intermediary processes (Bramwell et.al., 1996).

The prerequisite for an ecologically sustainable society is the use of eco-cycles in such a way that their functioning is not damaged irreversibly. It is not easy to operationalise this starting-point. Certainly, the discharge of materials, which are alien or rare in eco-cycles and mainly extracted from the stocks of fossil natural resources, should be minimised, or even better, stopped. However, it is impossible to recycle completely all materials. During production, consumption and recycling processes surely a certain part of the materials will be "lost", that is, end up in the eco-cycles. Technological development should be directed to a continuous decrease of the percentage of "lost" materials. Ultimately, the sustainable solution is to convert completely to renewable resources. Renewable resources can be extracted from the ever-functioning eco-cycles (on the condition of careful exploitation) and subsequently, after being used in production and consumption processes, they can be disposed of without exceeding the carrying capacity.

Traditional cost-benefit analysis cannot solve the problem of the determination of the optimal pollution point. Indeed, the price mechanism does not give sufficient information for this purpose. There is only one way to attempt to prevent overexploitation of the ecological utilisation space: specified standards which are considered to be sustainable from an ecological point of view. This implies that standards are directly derived from the functioning of the eco-cycles. Critical loads, carrying capacities, emission standards and extraction quotas are the policy goals in this respect. Subsequently, both 'command and control' instruments and economic instruments could be used to attain these policy goals. The choice between them, or better, the specific mix of them, depends on criteria, such as effectiveness and efficiency (Modinos, 1996).

Therefore, there is a need to maximise the benefits from tourism whilst the disbenefits or costs should be minimised, and to limit tourism development to within standards considered to be sustainable. Some of the environmental arguments for sustainable tourism will now be explained.

The tourism sector has specific features, which may lead to adverse impacts on social and natural resources. For instance, unlike other economic activities, the consumers have to travel to the product, which means that tourism can be highly intrusive in host communities and damage the environment in several ways. Tourism is also a diverse and fragmented industry, difficult to control. It comprises a number of independent and inseparable activities: travel, accommodation, catering, sightseeing and other services. Consequently, firms providing tourist goods and services belong to different industrial sectors and several of these firms also cater to the local population. Moreover, tourism is more or less seasonal in nature taking place at certain periods within the year, so the impacts can be temporarily concentrated in specific seasons. McKercher (1993) has asserted that tourists at present are strongly motivated by desires to escape from their everyday existence and to be entertained, suggesting that as a consequence they are relatively unconcerned about the social and environmental impacts of their tourist activities. In terms of environmental impacts, tourism interacts with the 


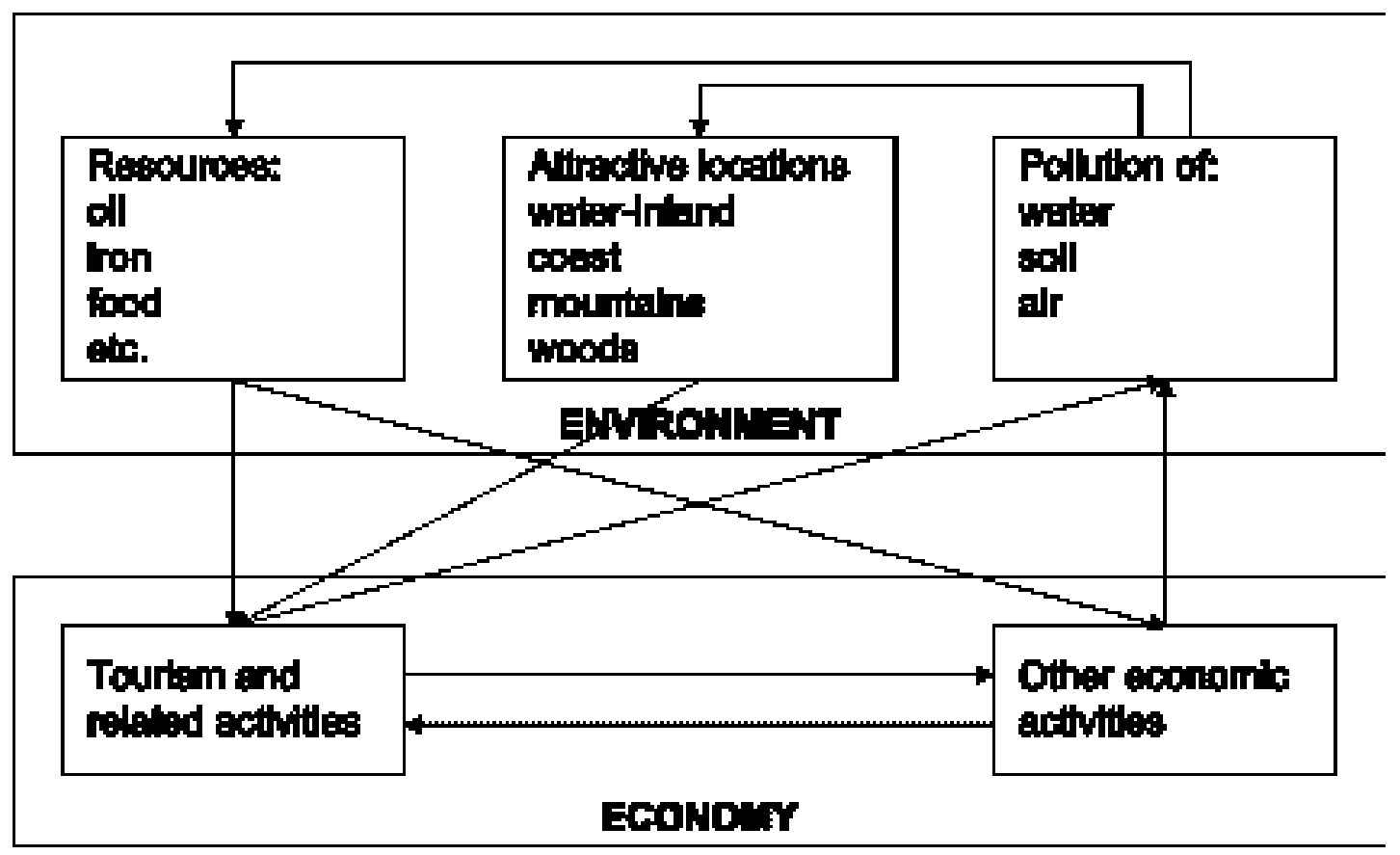

Figure 2. Interactions of tourism with the environment (Bramwell et.al., 1996)

environment in several ways, which are depicted in Figure 2. Two broad classes of interactions are noted: the direct interaction of tourism with the environment, and the effects of other economic activities on tourism through the environmental modifications they produce. It should be noted that the environment is used directly as a primary input within the tourist industry: First of all, all tourist infrastructures and superstructures utilise land. However, certain tourist land uses conflict with one another, even though they serve the same purpose of tourism development. This is the case, for example, when a highway, built to serve a tourist destination, is located close to a tourism development zone. Although proper land use planning can prevent conflicts from arising, this is not always possible.

\section{THE EUROPEAN CONTEXT TO SUSTAINABLE TOURISM}

For almost half a century, Europe has been the world's leading tourist destination. According to European Commission figures in 1992, tourism generated $5.5 \%$ of the then European Community's national income, accounted for $8 \%$ of end-user consumption, and employed 7.5 million full-time workers and 10 million if secondary activities were taken into account (Barnes and Barnes, 1993). The growing importance of tourism in Europe and the increasing awareness of its significance are reflected by the fact that it is cited for the first time in broad framework legislation in the treaty of the European Union (EU). Thus, it is vital that efforts are put into developing approaches to sustainable tourism management and also to implementing these at the European level (Lavery, 1993).

Sustainable tourism issues are important at the European scale:

- In environmental terms. A European dimension to sustainable tourism is necessary, as environmental problems do not respect national boundaries. The Maastricht Treaty introduced the 'sustainable development' concept as a major policy objective and now contains a requirement for the integration of environmental protection in other policies, moving the term forward to its preamble at the Amsterdam Summit.

- In economic terms. A sustainable tourism approach is likely to be essential to the longterm competitiveness of the tourism industry in Europe. Sustainable tourism may also be regarded by policy makers as a means of cor- 
recting economic imbalances between European regions without it producing adverse environmental, social and cultural effects on host communities. Conflicts between the local economies and the interests of 'outside' investors must be resolved in the best interests of the local economy and the quality of the environment. The transnational character of tourism businesses makes necessary a European-wide policy framework. For instance, the European Union is concerned to ensure that businesses carry external costs, which are broadly equal in different national contexts. The European Commission White Paper Growth, Competitiveness, Employment 1993 reminded the need to ensure that environmental legislation affecting businesses is consistent between Member States. Without this consistency, businesses may tend to move wherever environmental standards and hence costs are lowest. Since this will threaten jobs and income in Member States with higher standards, it will put a downward pressure on environmental protection.

- In social terms. The confinement of social problems as regional unemployment and depopulation may be favoured through sustainable tourism, particularly as the industry is located in many areas of Europe which have problems of underdevelopment and high levels of unemployment. Disadvantaged areas are the focus of the EU's regional policy, which is aimed at reducing intra-regional inequality.

- In political terms. Sustainable tourism may promote political participation, which is regarded as an essential feature of liberal democracy. This is particularly important when policy initiatives are promoted on a panEuropean scale. In this respect, new communication technologies and networking may prove particularly favourable.

Tourism is already affected by EU policy in a number of areas. This includes regional policy and its European Regional Development Fund arm, the Common Agricultural Policy, consumer policy (such as the directive on package holidays and package tours which was adopted in 1990), environmental policy (such as the 1976 directive on bathing water quality), social policy (in areas such as the rights of migrant workers and the mutual recognition of qualifications within the European
Union) and European monetary policy (for example, attempts to stabilise currencies through the Exchange Rate Mechanism). In many instances these policy areas may be more significant than measures directed specifically on tourism, such as the European Year of Tourism (1990) and the Community Action Plan to Assist Tourism (1991), the inclusion of tourism in the Treaty of Maastricht (Article 3), and the development of the European Commission Green Paper. However, there has been considerable debate within the EU about the principle of subsidiarity, which means that intervention should not interfere with decisions best made at the local, regional and national levels and this mirrors discussion among advocates of sustainable tourism about the relative decision making powers that should be held at the regional, national and international levels.

\section{CONCLUDING REMARKS}

Sustainable tourism, as the term suggests, attempts to confer an aura of respectability on tourism. Its principles of small scale, gradual and more equitable development, as opposed to large scale, rapid development appears very laudable. However, faced with the rapid growth of mass tourism, its feasibility is often questioned. Sustainable, Green or Eco-tourism focuses on the need to promote a symbiotic, or, at worst, co-existent relationship between tourism and environmental conservation. Tourism companies are increasingly responding to green consumerism and are anxious to promote an environmentally friendly image in their marketing strategies. Amongst such examples are the collective promotion of selected companies under the 'Green Flag' umbrella in the UK and the commitment of Swissair to present a corporate image of an environmentally conscious operation. Again there is a danger that such exercises may not go beyond marketing tactics, involving 'window dressing' in response to consumer pressure. Ecotourism has become "big business". It is the fastest growing sector of tourism, and has consequently generated unprecedented interest in the travel trade. Commercial pressures may well dictate that ecotourism will merely replicate the economic, social and physical problems associated with conventional tourism. The only difference, and herein lies perhaps the greatest threat, is that previously underdeveloped areas, all the more vulnerable, 
become the prime targets. And this process may be facilitated by the improvement of the telecommunications infrastructure.

It can be said that whilst Green or Ecotourism may satisfy environmentalists' claims it may not constitute sustainable tourism development. Unless a more holistic approach is taken, incorporating the needs of the host population, sustainability will be compromised. And this holistic approach should include equity considerations, a modernisation of the sector and the inevitable inclusion of new technologies in the production system. New forms of intra-regional co-operation could then arise, networks might be formed and sustainable development could shift emphasis from heavy infrastructure to good telecommunication systems, renewable energy, recycling processes, organic agriculture and nature protection schemes. In any case sustainable tourism is essential to the medium and long-term survival of this economic sector in Southern Europe.

\section{REFERENCES}

Ascher, F. (1985), Tourisme transnational corporations and cultural identities, UNESCO.

Barnes, I. and Barnes, P. (1993), Tourism Policy in the European Community, In: Tourism in Europe: Structures and Development, Pompl, W. and Lavery, P. (eds.), Wallingford, CAB International.

Blowers, A. (1993), Environmental Policy: The Quest for Sustainable Development, Urban Studies, 30, 775-796.

Boulding, K.E. (1966), The Economics of the Coming Spaceship Earth, In: Environmental Quality in a Growing Economy, Jarratt, K. (ed.), Baltimore, John Hopkins Press.

Bramwell B. et al. (1996), Sustainable Tourism Management: Principles and Practise, University Press, Tilburg, The Netherlands.

Cronin, L. (1990), A Strategy for Tourism and Sustainable Developments, World Leisure and Recreation, 32,12-18. DGXXIII (1995), Green Paper on Tourism, Brussels, European Commission.

Dobson, A. (1990), Green Political Thought, London, Unwin Hyman.

Drake, S.P. (1991), Local Participation in Ecotourism Projects, In: Nature Tourism: Managing for the Environment, T. Whelm (ed.), Washington D.C., Island Press.

Drepper, F.R. and Mansson, B.A. (1990), On the Role of Unpredictability in Environmental Economics, presented at the conference: Economics and the Environment, 17-19 September 1990, Centre for Economic Research, Tilbur University.

Eber, S. (ed.) (1992), Beyond the Green Horizon: Principles for Sustainable Tourism, Godalming, Surrey, World Wide Fund for Nature.

Ecotourism Society (1992), Definition and Ecotourism Statistical Fact Sheet, Alexandria, VA, Ecotourism Society.

Hemingway, S. (1997), Sustainable Tourism Education in the Mediterranean, F.O.E. MEDNET (in press).

Hunter, C. and Green, C. (1992), The Environmental Impact Assessment of Tourism Development. In: Perspectives on Tourism Policy, P. Johnson and B. Thomas (eds.), London, Mansell.

Inskeep, E. (1991), Tourism Planning: An Integrated and Sustainable Development Approach, New York Van Nostrand Reinhold.

Jacobs, M. (1991), The Green Economy, London, Pluto Press.

Kuik, O. and Verbruggen, H. (eds.) (1991), In Search of Indicators of Sustainable Development, Dordrecht, Kluwer Academic Publishers.

Lorch, I. (1995), Sustainable Tourism in Europe.

Lavery, P. (1993), A Single European Market for Tourist Industry, In: Tourism in Europe: Structures and Development, W. Pompl and P. Lavery (eds.), Wallingford, CAB International.

Lindberg, K. and Hawkins, D. (1993), Ecotourism: A Guide for Planners and Managers, N. Bennington, Vermont, The Ecotourism Society.

McKercher, B. (1993), Some Fundamental Truths About Tourism: Understanding Tourism's Social and Environmental Impacts, Journal of Sustainable Tourism, 1, 6-16.

Modinos, M. (1996), The Archaeology of Development, Cretan University Press, Athens, (in Greek).

Opshoor, J.B. and II. Vos (1989), Economic Instruments for Environmental Protection, Paris, OECD.

Romeril, M. (1989), Tourism and Environment: Accord or Discord?, Tourism Management, 10, 204-208.

Sachs, I. (1984), The Strategies of Ecodevelopment, Ceres, FAO Review on Agriculture and Development, 17, 17-21. 
Simmons, D.G. (1994), Community Participation in Tourism Planning, Tourism Management, 15, 98-108.

Soderbaum, P. (1982), Ecotourism Imperatives for Public Policy, Ceres, FAO Review on Agricultural and Development, 15, 28-32.

Steele, P. (1995), Ecotourism: An Economic Analysis, Journal of Sustainable Tourism, 3, 29-44.

Kenchington, R.A. (1989), Tourism: Passport to Development?, Oxford University Press, New York.

Rees, W.E. (1990), The ecology of sustainable development, The Ecologist, 20, 18-23.

Wheeler, B. (1991), Tourism's troubled times, Tourism Management, June 1991, 91-96

World Commission on Environment and Development (WCED), (1987), Our Common Future, Oxford University Press, Oxford. 